\title{
SHWARTZMAN REACTION AFTER HUMAN RENAL HOMOTRANSPLANTATION*
}

\author{
Thomas E. Starzl, M.D., Ph.D., Richard A. Lerner, M.D., Frank J. Dixon, M.D., \\ Carl. G. (;roth, M.D., Lawrence Brettschneider, M.D., and Paul I. Terasaki, Ph.D.
}

\begin{abstract}
In three human recipients, five renal homografts were destroyed within a few minutes to hours after their revascularization in the new host. The kidneys, removed one to 54 days later, had cortical necrosis. The major vessels were patent, but the arterioles and glomeruli were the site of fibrin deposition. There was little or no fixation of host immunoglobulins in the homografts. The findings were characteristic of a generalized Shwartzman reaction.
\end{abstract}

$\mathrm{R}$ ECENTLY, there have been several reports of "hyperacute rejection" after human renal homotransplantation. In some of these cases the homograft sustained an irreparable injury while the pattient was still on the operating table. ${ }^{1-4}$ In cases in which major red-cell group compatibility existed

* From the Department of Surgery. University of Colorado School of Medicine and the Denver Veterans Administration Hospital. Denver. Colorado. the Department of Experimental Pathology. Scripps Clinic and Research Foundation. La Jolla. California. and the Department of Surgery. School of Medicine. University of Californial. Los Angeles laddress reprint requests to Dr. Starzl at Veterans Administration Hos. pital. 1055 Clermont Street. Denver. Colorido 8()?20)

This is publication No. 261 from the Scripps (linic and Research Foundation.

Supported hy grants (AM-06283, AM-06344. HF-07735. AN1 (17772. Al-04152. FR-0(0)5I. FR-00064. F(05-TW-1154. Al-07007 and 5TI GM683): from the United States Public Health Service by AEC Contract AT (04-3)-4I0 and hy AID Contract PH 436.5994
Although the cause (or causes) of the Shwartzman reaction in our patients is not known, they may have been conditioned by the bacterial contamination and hemolysis that often attend hemodialysis, by immunosuppression and by the transplantation itself. Some of the patients have pretormed lymphocytotoxic antibodies. Thus, certain patients may be predisposed. High-risk patients should be recognized and treated prophylactically with anticoagulants.

between the donors and recipients, such a complicattion was not recognized in the first 180 calses of renal transplantation at the University of Colorado. Then, within an interval of six and a half weeks, five homografts were destroyed in three patients within minutes or hours after their revascularization.

It has been suggested ${ }^{2-4}$ that these immediate disasters were due to the direct cytotoxic action of preformed antibodies in the host that reacted against histocompatibility antigens present in the transplanted kidney. The state of advance sensitization to these specific antigens was presumalbly induced during the course of multiple pregnancies, by the previous administration of multiple blood transfusions or by other means such as prior renal homotransplantation. Where pathological reports were 
given, the morphologic conseguence of the supposed acute antigen-antibody. reactions included extensive destruction of the homograft vasculature. ${ }^{2.4}$

In the homografts of our own patients, the most striking finding was extensive intravascular deposition of fibrin, causing occlusion of most of the glomerular capillaries and consequent cortical necrosis exactly as occurs in the experimental generalized Shwartzman reaction. ${ }^{5}$ There was little or no host immunoglolulin deposition in the five kidneys removed 24 hours to eight weeks after transplantation.

Recognition that this complication may occur is important for several reasons. In the first place, experimental observations and the present clinical experience indicate that the Shwartzman reaction can be prevented and even in part reversed with appropriate anticoagulant or fibrinolytic therapy. Secondly, several factors that may contribute to its development can be eliminated or at least minimized by atteniion to details of preoperative care. Finally, the failure of function of a kidney involved in the Shwartzman reaction should not necessarily be attributed to a poor histocompatibility match since a variety of other immunologic and nonimmunologic factors may be contributory.

\section{Case Reports}

CASE 1. A 15-year-old girl had an 11-year history of progressive renal disease. Hemodialysis was instituted, a saline prime being used for the lst run on the twin-coil artificial kidney. At the end of this and 12 subsequent pretransplantation hemodialyses, the residual blood in the extracorporeal circuit was bottled and stored in the refrigerator. From 1 to 5 days later it was used to prime the artificial kidney at the time of the next treatment.

The child was $\mathrm{A}^{+}$red-cell type. Her Ist homograft was provided by her 52 -year-old mother, whose blood group was ()+. With the use of a lymphocvite critotoxicity test, a mismatch

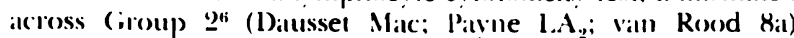
antigen system was demonstrated. No preformed lymphocytotoxic antibodies could be demonstrated in the recipient's serum. For 5 days before transplantation horse antihumanlymphocyte globulin (ALG) was administered intramuscularly to the recipient patient as recently described. ${ }^{7}$ Azathioprine was started on the evening before transplantation.

There were no technical misadventures during transplantation. While the renal vascular anastomoses were being performed, $50 \mathrm{mg}$ of prednisolone and $12.5 \mathrm{gm}$ of mannitol were given intravenously. When blood flow was restored to the kidney after a cold ischemic interval of 30 minutes, the organ was homogeneously perfused. However, within 5 minutes the homograft lost its turgidity and became diffusely cyanotic except for the pelvis and ureter. An additional 750 $\mathrm{mg}$ of prednisolone was given intravenously without improvement. Urine was never produced. The homograft was removed 48 hours later. The major vessels were patent. Grossly, there was complete cortical necrosis.

Later on the same day a cadaveric homograft became available from a donor of $A^{*}$ red-cell type. As with the lst homotransplantation, there was a lymphocyte antigen incompatibility across the Group 2 (Mac) system. After revascularization the cadaveric homograft produced urine for 2 hours, and then ceased functioning. When it was removed 18 days later there was complete cortical necrosis. Between the 2 transplantations and during the month after excision of the 2d kidney, multiple serum samples were examined for lymphocytotoxic antibodies. These could not be detected.

Fifieen dass after removal of the eal homogratit. a special precedure wis performed. with the use of the plassic arteriovenous shunt employed for hemodialysis to determine the feasibility of a later definitive transplantation. Both kidneys were removed from a 14-month-old cadaveric donor of $\dot{A}^{+}$ blood type who had lymphocyte antigen incompatibilities with the recipient in Groups 2 (Mac) and 5 (Dausset 9-10; Payne 4d; van Rood 6b-c) systems. One kidney was placed into the recipient's circulation by connection of its vessels to the arterial and venous limbs of the brachial shunt. The organ became well vascularized, and within the next $3 \frac{1 / 4}{4}$ hours, it produced $95 \mathrm{ml}$ of urine. It was removed and studied with light microscopy and immunofluorescence technics.

The $2 \mathrm{~d}$ kidney from the same cadaveric donor, which had been preserved in a hyperbaric oxygen chamber at $4^{\circ} \mathrm{C}$. for $3 \frac{1}{2}$ hours, was then similarly inserted. It remained well perfused for 2 hours, elaborated $360 \mathrm{ml}$ of urine and provided a creatinine clearance of $5.9 \mathrm{ml}$ per minute. The $2 \mathrm{~d}$ homograft was now removed, flushed clean of blood and placed back in the hyperbaric chamber. Twelve hours later it was reinserted into the arteriovenous shunt for 2 hours. It elaborated $265 \mathrm{ml}$ of urine and had a creatinine clearance of $3.5 \mathrm{ml}$ per minute. It was again removed, preserved for

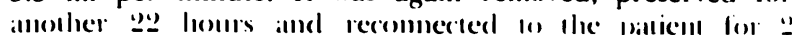
hours. This time it produced $210 \mathrm{ml}$ of urine and provided a creatiunine cleatrance of $2.5 \mathrm{ml}$ per minute. The pitlhologic changes in these 2 extracorporeal kidneys are described below.

for 10 weeks after the lst 2 intricorporeal kidners had been destroyed by a Shwartzman reaction, the patient received special dialysis precautions, including the avoidance of reused blood, priming of the antificial kidnes with whitecell-fiee blood and calleful monitoring of dialssis baulss for possible bacterial comtamination. ()n December $2 x$. 196it, al 3d intracorporeal kidner wils transplanted from all ()+ (aidaveric donor. There were no mismatches in the HLA leukocyte antigen systent ${ }^{6}$ although there were several incompatibilities as detected with unclassified antiserums. The patient was heparinized during the operation and for the next 3 days. She has had excellent renal function for the first 4 postoperative weeks. The immunosuppressive therapy was similar to that used previously except that prednisone was not given for the lst 24 hours.

CASE 2. A 31-yeal-old man of ()- blexel lype received a lomografi from his 35-veatr-old brother, whio wals also (1)The circumstances were similar to those in Case 1. The recipient had been on chronic hemodialysis for 8 months; reused blowel wals not used to prime llice antilicial hidnes for the last 4 dialyses. A Group 2 (Mac) incompatibility was presem. At the time of testing. "2 momths before transplantation, the recipient did not have preformed Ismphosviotoxic antibodies, but a later check of stored serum obtained on the day before operation showed that such antibodies had developed in the interval.

Within I minute after revascularization, the homograft became cyanotic. Prednisolone, $1.5 \mathrm{gm}$, and papaverine, 250 $\mathrm{mg}$, were injected into the renal artery without effect. The organ, which was removed 24 hours later, had patent major vessels and total cortical necrosis. The cytotoxic antibodies present before operation have continued to be found in the recipient serum to the present day.

fighteen datss after the original transplantation. an extra-

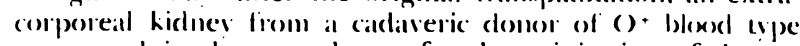
was tested in the arm shunt after heparinization of the recipient. Donor-recipient lymphocyte antigen incompatibilities were in the Group 2 (Mac) and 3-4 (Dausset 3; van Rood 4a) systems. The kidney remained well vascularized and elaborated urine. It was removed $2 \frac{1 / 4}{4}$ hours later.

Seven weeks after the original operation, a final homo- 
graft from the patient's blood-group-compatible niece was transplanted; there was a mismatch in the HLA system of the Group 5 antigen. Before revascularization, $3 \mathrm{mg}$ per kilogram of heparin was given intravenously. A Shwartzman reaction did not develop then or in the subsequent 6 weeks.

CASE 3. A 24-vear-old multipara was on chronic hemodialysis for 15 months with pump priming by reused blood. Uncontrollable ascites developed. When a blood group com. patible cadaveric donor became available, renal homotransplantation was carried out under the same general conditions as in Cases 1 and 2 except that A.L.; was not given before operation. The donor-recipient lymphocyte antigens were compatible for all 6 major HLA leukocyte antigen systems. The transplanted kidney diuresed promptly but became anuric within 18 hours.

Ten days later a 2d cadaveric homograft was placed on the opposite side. All 6 of the major leukocyte antigen groups were again compatible although there were a few incompatibilities as measured with unclassified antiserums. This kidney also functioned within a few minutes, but by the time the wound was closed several hours later, a faint diffuse cyanosis was evident on its surface and it had become soft. Urine flow permanently ceased 2 hours later. Immunosuppressive therapv was given with azathioprine, prednisone and ALG until the patient died 54 days after the initial transplantation. At autopsy the lst homograft had complete cortical necrosis; in the $2 d$ homograft the same process was present but incomplete.

\section{Pathological Observations}

Parts of the patients' own kidneys and each of the homografts were frozen and studied with immunofluorescence technics. The other portions were formalin fixed for light microscopy. In Cases 1 and 2 the patients' kidneys were removed approximately two hours before revascularization of the homografts, and in Case 3 the autologous kidneys were removed seven weeks after the first transplantation, both homografts having already been destroyed by the Shwartzman lesion described below. There was some fibrin deposition in these organs, but this is a common pathological finding with end-stage nephritis and does not necessarily imply a Shwartzman lesion.

All five of the homografts placed intracorporeally in Cases 1-3 were the site of a generalized Shwartzman reaction. Grossly, there was complete or nearly complete cortical necrosis. The histopathologic lesions were similar in each of the homografts. By light microscopy the anatomic diagnosis of cortical necrosis was confirmed. Fibrin could be shown to be present in most glomeruli with the phosphotungstic acid hematoxylin stain (PTAH) (Fig. 1). The capillaries of many glomeruli were filled with fibrin, and in some there was marked infiltration of polymorphonuclear leukocytes (Fig. 2). The walls of the cortical arterioles were also the site of fibrin deposition and extensive necrosis.

Frozen tissues from the homografts and from normal human kidneys were stained with fluorescein isothiocyanate-conjugated rabbit antibody against human gamma $a_{i:}$ globulin (IgG), beta ${ }_{1}$ complement $(\beta, C)$ and fibrin. The predominant finding of all the homografts was fibrin in the glomeruli and cortical

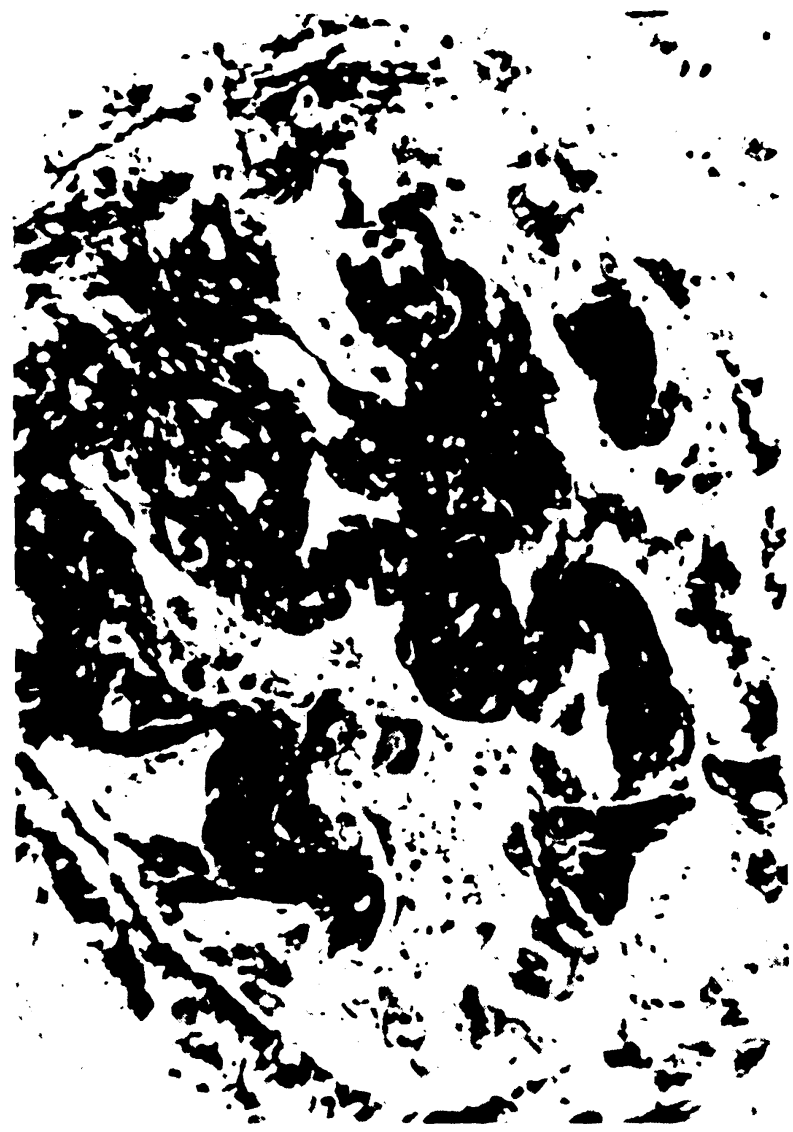

Figure 1. cilomerulus from the Serond Homograft Remozed from

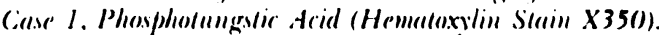

Nole the heary deposition of fibrim in this ghomerulus.

arterioles. In the glomeruli, this ranged from deposition along the basement membrane (Fig. 3), through extensive occlusion of the capillary loops (Fig. 4) to complete replacement of the glomerular architecture (Fig. 5). Faint traces of $\mathrm{IgG}$ and $\beta_{1} \mathrm{C}$ could be detected in some glomeruli as well as some arterioles, but the small amounts suggested that these were the result of protein "trapping" and not a specific immunologic reaction. There was no staining when control kidneys were studied with the same reagents used to study the homografted kidneys.

The first cadaveric infant homograft temporarily placed on the arm of the nonheparinized Case 1 did not suffer a Shwartzman reaction, nor did the contralateral donor kidney that was then similarly placed three times during the next two days; the extracorporeal cadaveric kidney tested after heparinization of Case 2 was also spared from fibrin deposition. There was no detectable immunoglobulin deposition in the three extracorporeal homografts. These findings were of particular interest in Case 2 since, as mentioned earlier, he had preformed cytotoxic antibodies.

Serums from all three patients were examined for antiglomerular basement-membrane antibodies before and after each of the intracorporeal and extra- 


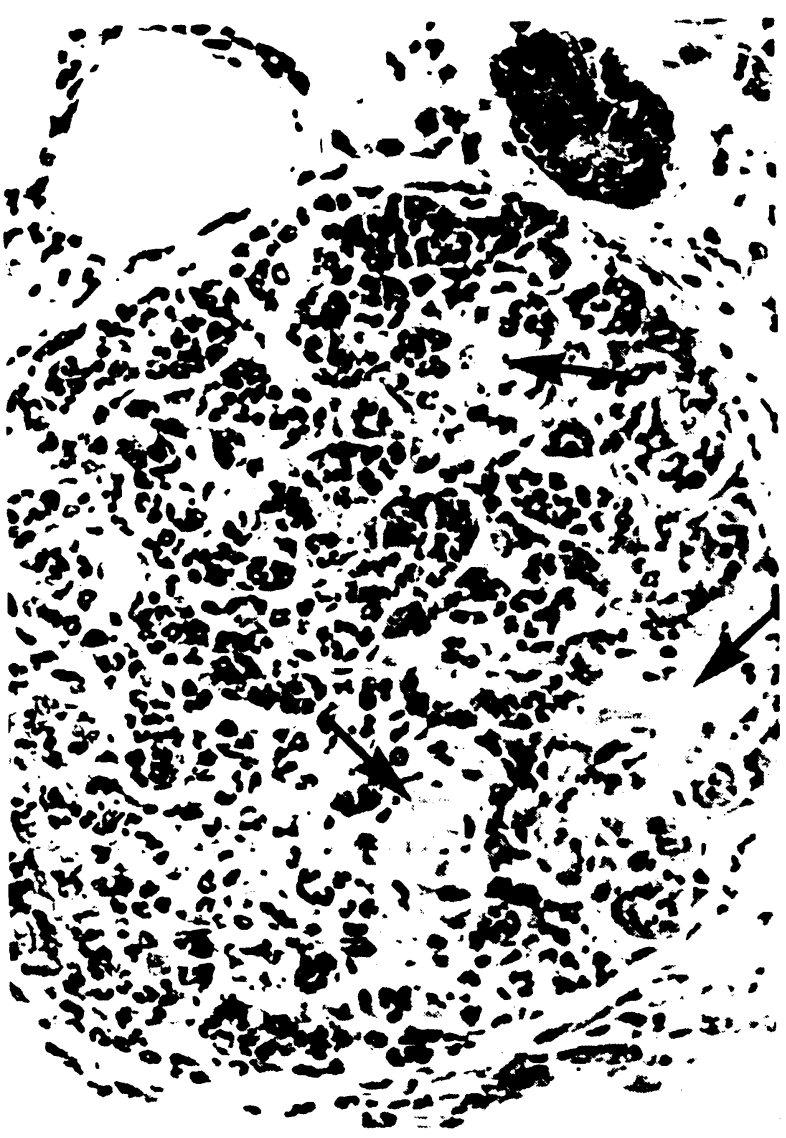

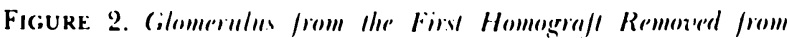
(inse 1 (Hemaloxilin and Easinl Slarin X350)

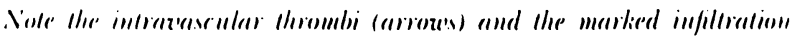

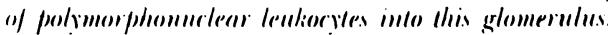

corporeal transplantations. These could not be detected.

\section{BACTERIOLOGIC STUdies}

After the diagnosis of Shwartzman reactions had been made, extensive studies were undertaken to rule in or out the possibility that the patients had been contaminated with bacteria or bacterial products. In Cases 1 and 2 , samples were available of blood retrieved from the artificial kidney after one or more of the final pretransplantation hemodialyses. These as well as four other bottles of reused blood saved from other patients on chronic hemodialysis were sterile. A similar.blood sample was examined after a hemodialysis immediately before Carse 3 died, eight weeks after the first homotransplantation. There was a heavy growth of Escherichia coli and enterococci. In this case, it was probable that the patient had septicemia before the final dialysis.

The plasma was removed from each of the foregoing sterile samples, and $3 \mathrm{ml}$ was given intravenously to trained rabbits, which were confined to fever cages. None of the serum samples used caused hyperpyrexia. As a positive control, hyper-

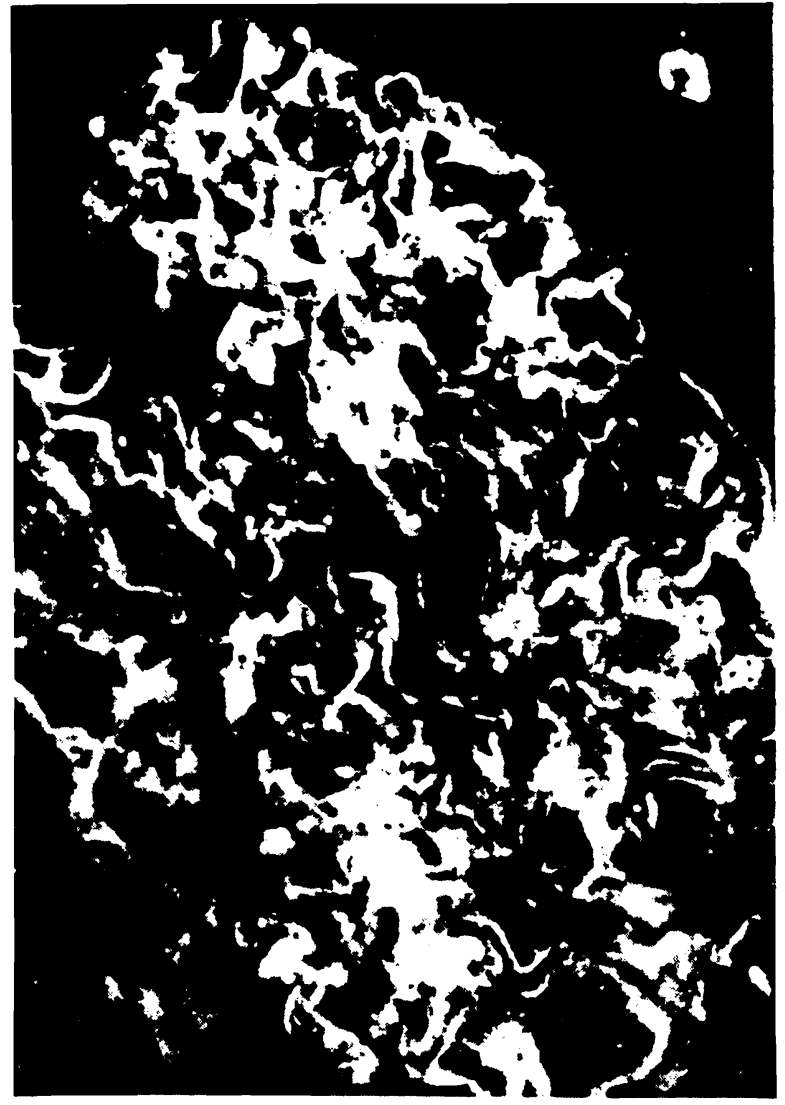

Figure 3. Cilommerulus from lhe Firsl Homograll Remoned from

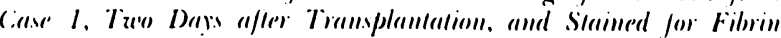
$(X+()())$.

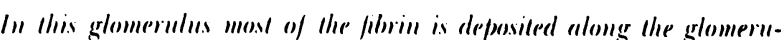
lai basement membrames.

pyrexia was subsecquently caused in each rabbit by the intravenous injection of commercial endotoxin.

Cultures of the dialysate baths were reviewed for the eight-week period during which Cases 1-3 were treated on the artificial kidney. Growth of gramnegative micro-organisms was invariably present, the most common bacteria being Aerobacter-Klebsiella, Pseudomonas aeruginosa, E. coli and paracolon strains.

Cultures were also made on multiple vials of the ALG then being administered, as well as on the crude horse serum from which this ALG was manufactured. All cultures were sterile. The ALG was nonpyrogenic in rabbits. Shwartzman reactions were not caused in rabbits by paired intravenous injections of $5 \mathrm{ml}$ of ALG at 24-hour intervals.

\section{Discussion}

Renal homografts may be adversely affected in a variety of ways, including homograft rejection, the recurrence of nephritis and, as shown in the present report, the development of a Shwartzman reaction. These processes may occur separately or in any combination. That immunologic events similar to those causing the patient's original nephritis may 


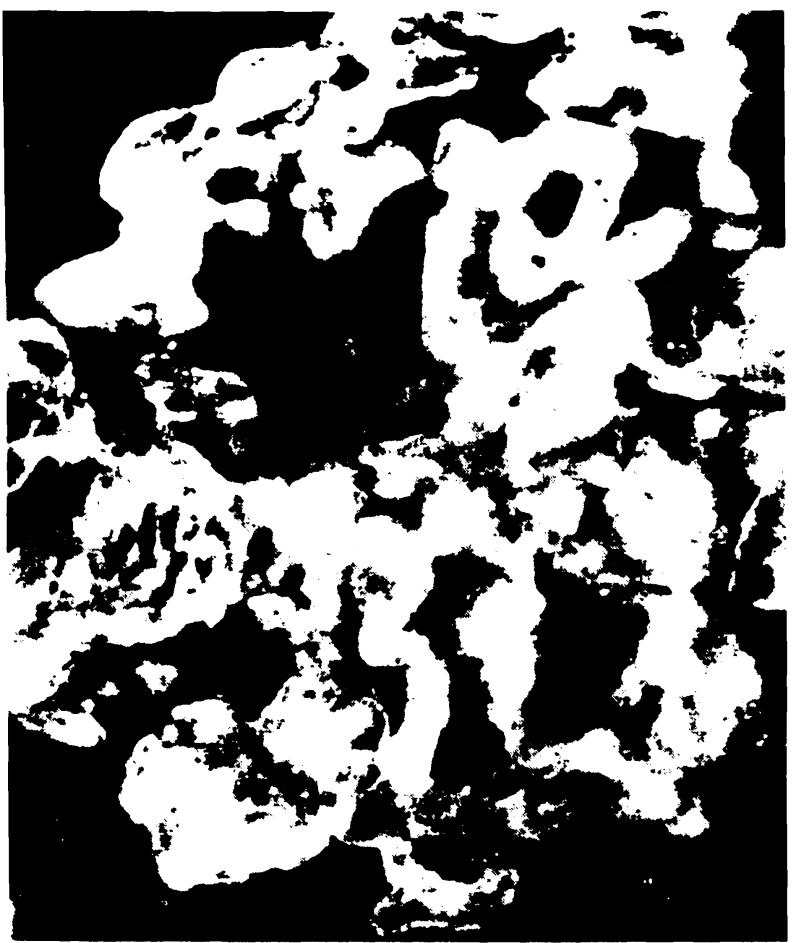

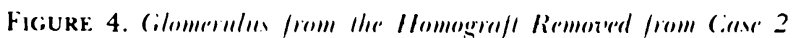

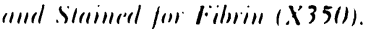

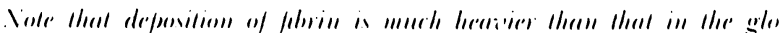

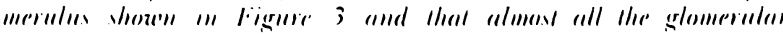
iapillarion are occhoded will fibrin.

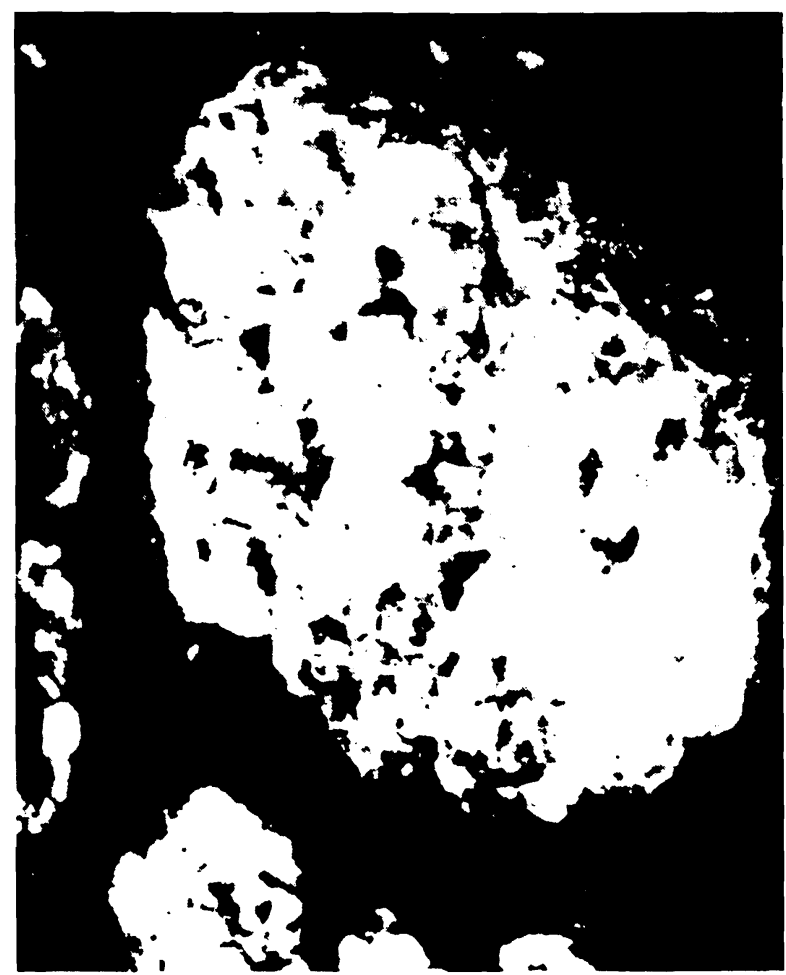

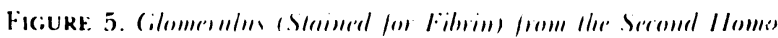

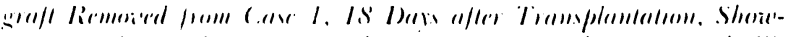

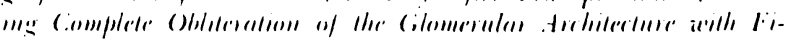
lin'1! $(.13(1))$. similarly affect the transplant has recently been demonstrated." In such situations the kidney is not rejected but goes through the familiar sequence of events of progressive nephritis modified by immunosuppression. Immumologic homograft rejection may proceed at varying rates, depending upon antigenic differences between donor and recipient, upon previous sensitization of the latter and upon effectiveness of immunosuppression. Here, the graft is presumalbly rejected by the direct cytotoxic action of sensitized cells or humoral antibodies or both.

The immediate failures described in the present report were due to Shwartzman reactions in that there was complete or nearly complete cortical necrosis secondary to massive deposition of fibrin in the small arteries and glomeruli.s." The terminal events in the Shwartzman reaction involve an increase in intravascular coagulation, usually in the presence of a compromised reticuloendothelial system that fails to clear fibrinogen products from the circulation as rapidly as they are formed. This results in occlusion by fibrin of many vessels, including the glomerular capillaries, and then renal cortical necrosis; the kidney is especially susceptible to injury because the properties of its microcirculation make it an exceptionally effective filter for the circulating fibrin. The factors that may prepare a subject for the Shwartzman reaction or precipitate it include bacterial endotoxins, antigen-antibody reactions, blockade of the reticuloendothelial system, steroids, pregnancy, oxidized lipid diets and epinephrine. ${ }^{5.9}$ Although the actions of some of these are not completely understood, most appear to induce a hypercoagulability state or a reduction in the efficiency of function of the reticuloendothelial system. In addition, hemodynamic conditions can modify the outcome of a Shwartzman experiment. Sympathectomy or vasodilating drugs protect against the Shwartzman reaction, and renal vasoconstriction predisposes to it. 9

The development of Shwartzman reactions in hilman recipients of renal homografts could be explained by an extrapolation of the foregoing information. The necessary practice of repeated preoperative hemodialysis predictably imposes in extra load on the reticuloendothelial system by increased hemolysis, ${ }^{10}$ and this is presumably exaggerated by the reuse of blood. Hemodialysis also causes changes in the coagulability of the patient's blood." Finally, there is a possibility of introducing endotoxin from such extracorporeal circuits. There have been reports of the difficulty of maintaining sterile dialysis baths, ${ }^{12,13}$ an especially important consideration since Kidd ${ }^{13}$ has demonstrated the ease with which bacterial products can pass through dialysis membranes. In our own cases, there was bacterial contamination of the baths although the presence of endotoxin could not be demonstrated in the blood subsequently retrieved from the artificial kidney. 
The events surrounding the actual transplantation probably have a special role in precipitating a Shwartzman reaction. Homografts that have already sustained an ischemic insult often do not have a normal blood flow in the early post-transplantation period. ${ }^{14}$ In addition, immunosuppressive agents are then part of the picture. These include prednisone, with its ability to produce paralysis of the reticuloendothelial system, ${ }^{1: 5}$ and azathioprine. In addition, ALG theoretically could be responsible for a triggering antigen-antibody reaction not only because the equine antibodies react with some of the patient's antigens but also beciause in imost patients antibodies against the repeatedly injected horse protein eventually develop. ${ }^{16}$ There was no reason, in fact, to implicate ALG in our cases because a Shwartzman reaction developed in one of the paltients before any ALG was given. Moreover, it has been learned that Shwartzman reactions have been seen at the Peter Bent Brigham Hospital ${ }^{17}$ and at other institutions where ALG is not in use.

Most importantly, the introduction of a foreign organ into the circulation could precipitate a latent Shwartzman reaction by initiating a variety of antigenantibody reactions. These could occur in the kidney by a mechanism similar to that demonstrated by Arhelger et al. ${ }^{18}$ in rats, which normally are resistant to Shwartzman reactions. In their experiments the antibodies were provided in nephrotoxic antiserum, which was given in combination with minute quantities of endotoxin. It is of interest that Williams et al. ${ }^{3,4}$ found host intibodies fixed in some of their human homografts that had been destroyed by "hyperacute rejection."

In our cases, however, the process was apparently not generated either by extensive binding of host antibodies to the kidneys or by serious histoincompatibilities. Little or no host immunoglobulin was detectable in the destroved homografts or in the kidneys later tested in an extracorporeal location. Furthermore, three of the five grafts that sustained Shwartzman reactions were thought to be from well matched donors; in the other two, there were mismatches only in the Group 2 (Mac) HLA system. Thus, if an intrarenal antigen-antibody reaction occurred in these kidneys, it was undetectable by our technics and, in all likelihood, of minor inherent significance except as an initiator for the devastating secondary events that followed.

In connection with the role of acute antigen-antibody reactions within or outside the kidney in precipitating Shwartzman reactions, it is of interest that a disproportionate percentage of patients in whom homograft destruction occurred immediately after revascularization have had preformed lymphocytotoxic antibodies. ${ }^{19}$ This situation occurred in Calse 2 of our series. One of us (P.I.T.) has recently collected 15 cases in which lymphocytotoxic antibodies were shown to be present in the recipients before homografts were placed. Eleven of the tramsplinted or- gans were immediately lost. The final lesion in such kidneys may well have been a Shwartzman reaction, a possibility supported by review of the microscopical reproductions and the descriptions in the earlier reports of Kissmeyer-Nielsen ${ }^{2}$ and Williamss respectively. Indeed, Kissmever-Nielsen et al. called attention to the Shwartzman-like character of the renal lesions.

Recognition that many and probably most "rejections on the operating table" are due to Shwartzman reactions has practical implications. It is evident that precautions should be taken before transplantation to avoid predisposing factors such as blood hemolysis and bacterial contamination. It is also likely that certain people have an unusual predisposition to this complication. These probably include patients with preformed lymphocytotoxic or antikidney antibodies. Our own experience, as well as that of several other American transplantation centers, indicates that a first Shwartzman reaction is very apt to be followed by a similar accident at the time of a second renal homotransplantation. Possibly, such high-risk recipients could be detected with preoperative immunologic studies or analyses of clotting or reticuloendothelial function. In such cases, prophylactic anticoagulants could be given. Once a Shwartzman reaction has begun, intraoperative anticoagulation or treatment with fibrinolysins may prove to be useful.5,9

\section{REFERENCES}

1. Terasaki. P. I., Marchioro. T. H., and Starzl. T. E. Sero-typing of human lymphocyte antigens: preliminary trials on long-term kidney homograft survivors. In Conference on Histocompatibility Testing. Washington. D. C., 1964. Histocompatibility testing: Report of a conference and workshop sponsored by the Division of Medical Sciences, National Academy of Sciences. National Research Council, 7.12 Jume. 1964. Conference on Histocompatibility Testing. Edited by P. S. Russell and H. J. Winn. Works/oop on Hislocomparibility Testing. Edited by D. B. Amos. Washington, D. C.: National Research Council. 1965. Pp. 83-95.

2. Kissmeyer-Nielsen. F.. Olsen. S.. Petersen. V. P.. and Fjeldborg. O. Hyperacute rejection of kidney allografts, associated with preexisting humoral antibodies against donor cells. Lailcet 2:662-665. 1966.

3. Williams, G. M.. et al. Studies in hyperacute and chronic renal homograft rejection in man. Surgery 62:204-212, 1967.

4. Williams, G. M., Hume, D. M., Kano, K., and Milgrom. F. Personal communication.

5. Lee, L., and Stetson. C. A. Local and generalized Shwartzman phenomena. In The Inflammatory Process. Edited by B. W. Zweifach. L. Grant and R. T. McCluskey. New York: Academic Press. 1965. Pp. 791.817.

6. Terasaki, P. I., Vredevoe. D. L., and Mickey, M. R. Serotyping for homotransplantation. X. Survival of 196 grafted kidneys subsequent to typing. Transplantation 5:1057-1070, 1967.

7. Starzl, T. E.. Porter, K. A.. Iwasaki, Y.. Marchioro. T. L.. and Kashiwagi. N. Use of antilymphocyte globulin in human renal homotransplantation. In Ciba Foundation. Antilymphocvtic Serum (bi) Study Group No. 9. Edited by G. E. W. Wolstenholme and M. J. O'Connor. London: $C$ hurchill. 1967. Pp. 4-34.

8. Lerner, R. A.. Glassock. R. J.. and Dixon. F. J. Role of antiflomerular basement membrane antibody in pathogenesis of human glomerulonephritis. J. Eiver. M/al. 126:989-10(1)4. 1967.

9. Hjort. P. F.. and Rapaport. S. I. Shwartzman reaction: pathogenetic mechanisms and clinical manifestations. Alln. Rer. Med 16:135-168. 1965.

10. Brown, E., Seidel. W., and Kolff. W. J. Hemolysis calused by 
pumps at flow rates of 2 liters. Tr. Am. Soc Artif. Int. Organs 7:350-354. 1961.

11. von Kaulla. K. N.. von Kaulla. E.. Wasantapruck. S.. Marchioro, T. L.. and Starzl. T. E. Blood coagulation in uremic patients before and after hemodialysis and transplantation of kidney. Arch. Surg. 92:184-191. 1966.

12. Sherris. J. C.. Cole. J. J.. and Scribner. B. H. Bacteriology of continuous flow hemodialysis. Tr. Am. Soc. Artif. Int. Organs 7:3740. 1961 .

13. Kidd. E. E. Bacterial contamination of dialyzing fluid of artificial kidney. Brit. M. J. 1:880-882. 1964

14. Lewis. D. H., et al. Value of renal blood flow measurement with xenon-133 at time of kidney transplantation. Ann. Surg. 166:6574. 1967.
15. Thomas, L., and Good. R. A. Effect of cortisone on Shwartzman reaction. J. Exper. Med. 95:409,427. 1952.

16. Kashiwagi, N.. Brantigan. C. O.. Brettschneider, L.. Groth. C. G.. and Starzl. T. E. Clinical reactions and serologic changes following administration of heterologous antilymphocyte globulin to human recipients of renal homografts. Ann. Int. Med. (in press).

17. Merrill. J. P. Personal communication.

18. Arhelger, R. B., Brunson, J. G., Good. R. A., and Vernier. R. L. Influence of gram-negative endotoxin on pathogenesis of nephrotoxic serum nephritis in rats. Lab. Investigation 10:669-687. 1961.

19. Terasaki. P. I.. Trasher. D. L.. and Hauber, T. H. Serotyping for homotransplantation. XIII. Immediate kidney transplant rejection and associated preformed antibodies. In Advance in Trunsplantaiion. Copenhagen: Munksgaard. 1968. Pp. 225-229. 